\title{
Outpatient Alcohol Detoxification: Implementation Efficacy and Outcome Effectiveness of a Model Project
}

\author{
Michael Soyka Michael Horak \\ Psychiatric Hospital, University Munich, Munich, Germany
}

\author{
Key Words \\ Alcohol · Alcoholism - Outpatient detoxification . \\ Community medicine
}

\begin{abstract}
Background: The aim of the study was to examine the practicability and implementation efficacy of an alcohol outpatient detoxification model and the concomitant 'motivational' psychotherapeutic approach. Method: This was an open prospective study to examine the implementation efficacy, practicability and medical safety of a novel psychotherapy-based, integrated outpatient detoxification model in alcohol-dependent patients. Patients were carefully screened for relevant neuropsychiatric disorders and other exclusion criteria and then seen on a daily outpatient basis for 5-7 days. Patients received psychotropic or other medication, if necessary (CIWA-A score $>16$ ). Beside management of withdrawal symptoms, psychotherapeutic interventions were conducted to motivate the patient for further alcohol therapy. Results: Of 557 patients screened 331 entered the program. For medical reasons 226 patients had to be admitted for inpatient detoxification, 122 patients in a special alcohol unit, 101 patients in a general hospital. $198(60 \%)$ of the outpatients received psychotropic medication during treatment. $312(94 \%)$ of these patients suc-
\end{abstract}

cessfully completed treatment. 301 (91\% of the initial sample) patients entered a consecutive 3-month motivational phase of a two-phase alcohol treatment program. 139 (46\%) patients successfully completed the 1-year consecutive outpatient treatment. Conclusions: Outpatient detoxification, at least in a highly structured frame, can be considered as a safe and efficient therapeutic approach. The data of this study also indicate that psychotherapeutic interventions and motivation for further abstinence and treatment may work in alcohol-dependent patients on an outpatient basis. Further controlled trials are necessary to compare the effects of outpatient versus inpatient withdrawal.

Copyright $\odot 2004$ S. Karger AG, Basel

\section{Introduction}

Alcoholism is one of the most widespread psychiatric disorders in Western countries. Current treatment services only partially meet patients needs. In a comprehensive review of alcohol treatment, McCrady and Langenbucher [1996] concluded that a reformed health care system should include full benefits for outpatient care which can be considered as an important task of community medicine. But the issue of outpatient detoxification is still controversial with most patients being treated in hospi-

\begin{tabular}{ll}
\hline KARGER & ( ) 2004 S. Karger AG, Basel \\
Fax +41 61306 1234 & \\
$\begin{array}{l}\text { E-Mail karger@karger.ch } \\
\text { www.karger.com }\end{array}$ & $\begin{array}{l}\text { Accessible online at: } \\
\text { www. karger.com/ear }\end{array}$
\end{tabular}

Michael Soyka, MD

Psychiatric Hospital University Munich

Nussbaumstrasse 7, DE-80336 Munich (Germany)

Tel. +49 8951602777 , Fax +49 8951605617

E-Mail Michael.Soyka@psy.med.uni-muenchen.de 
tals, at least in Germany and most other European countries. While favorable results of outpatient or day-hospital rehabilitation programs for substance use have been reported by Cornwall and Blood [1998], McKay et al. [1995, 1998], Ehrenreich et al. [2000] and Willenbring et al. [1995], among others, outpatient detoxification is still a widely neglected issue in alcohol therapy [Fiellin et al., 2000; Prater et al., 1999]. Wiseman et al. [1998] reported that $85 \%$ of 108 patients enrolled in an outpatient detoxification program successfully completed detoxification without medical complications. Using a symptom-triggered pharmacological treatment approach, only 38\% of patients received medication (chlordiazepoxide). In another sample of 577 patients consecutively referred to an ambulatory detoxification program, 453 completed outpatient detoxification [Wiseman et al., 1997]. Similarly Collins et al. [1990] reported a 79\% completion rate in a sample of 76 patients using a fixed-dose regime. Patients had initially received $30-40 \mathrm{mg}$ diazepam with gradual withdrawal over a 5- to 7-day period. Little is known about the mid- to long-term effects of outpatient alcohol detoxification. Collins et al. [1990] speculated that there were no particular reasons why outpatient detoxification should have any greater or lesser effect on long-term outcome than inpatient treatment, but currently there are few studies to support that notion.

Psychotherapeutic interventions are of great relevance for further treatment outcome. Current therapy recommendations suggest integrating psychotherapeutic 'motivational' elements into the detoxification period to motivate the patient for further therapy and abstinence [Feuerlein et al., 1998; John, 1991; John et al., 2000]. Based on the concepts of Miller and Rollnick [1991, 1999], motivational techniques today are integrated into the detoxification phase [Feuerlein et al., 1998]. In Germany the integration of motivational aspects into detoxification is named 'qualified detoxification' (qualifizierte Entgiftung) [Mann, 2002]. A number of different motivational approaches varying in their intensity have been integrated into the early intervention or detoxification of alcoholics [John, 1991; John et al., 2000]. A major aim of motivational therapy during detoxification is to increase the patients own activity towards further therapy and into the 'action phase' according to the concept of Miller and Rollnick [1991, 1999]. In Germany the efficacy of 1- to 3-week motivational therapy during inpatient detoxification has been studied [John, 1991; Schwoon, 1990] but similar interventions during outpatient detoxification have not been the subject of research.
We report data of a psychotherapy-oriented alcohol outpatient program which was supported as a model project by major health insurances. This article describes the methods of the program and offers results on feasibility and outcome. Following the implementation of a structured outpatient detoxification program in an outpatient clinic, a prospective 1-year evaluation study on the applicability of this program and clinical outcome of the patients was performed.

\section{Subjects and Methods}

This was an open, prospective study to examine the implementation efficacy, medical safety and practicability of outpatient detoxification of alcohol-dependent patients.

The major aims of the study were to evaluate: (1) the acceptance and efficacy of outpatient alcohol detoxification; (2) the number of patients screened and included; (3) the number of patients successfully detoxified, and (4) the medical complications.

The efficacy of the concomitant psychotherapeutic approach was also evaluated. Patients were examined 12 months after detoxification to assess whether (1) they had completed the consecutive 1-year outpatient rehabilitation program for alcohol dependence, and (2) were abstinent or had relapsed at follow-up.

\section{Inclusion Criteria}

Patients had to meet ICD-10 [Dilling et al., 1994] and DSM-IV [American Psychiatric Association, 1994] criteria for alcohol dependence. Patients were requested to be willing to participate in an outpatient treatment and detoxification for alcohol dependence. Also one close relative (spouse, etc.) or friend was required as support for the patient at home (not mandatory).

\section{Exclusion Criteria}

Polysubstance use, history of severe alcohol-related disorders (seizures, alcohol psychosis), major psychiatric disorders (e.g. schizophrenia, suicidality), severe cognitive deficits, severe medical disorders (pneumonia, tuberculosis or other infectious diseases), head injury, severe liver cirrhosis, erosive gastritis, pancreatitis, reduced physical state and cardiovascular disorders were reasons for exclusion.

\section{Treatment Facility}

The treatment facility is an outpatient clinic (Klientenzentrierte Problemberatung Dachau, KPB, Fachambulanz für Suchterkrankungen) specialized in the treatment of substance use disorders which offers a comprehensive two-step rehabilitation model for alcohol dependence: A 3-month motivational treatment phase was followed by a 6- to 9- (mean 8)-month rehabilitation program (80-120 group and individual therapy sessions). The motivational phase is usually paid for by the health insurers, the rehabilitation phase by pension funds.

Details of the program have been described elsewhere [Soyka et al., 1997, 2002]

\section{Motivational Phase}

The motivational phase starts immediately after outpatient detoxification. During the motivational phase patients are seen several 


Screening
Examination and Diagnosis

- Breathalyzer, drug screening
- Diagnosis of alcoholism? (ICD10)
- ECG: Heart rhythm disturbance? Laboratory:
Hypokalemia?
- Risk scale: Grading of risk of a heavy withdrawal
syndrome
- Withdrawal scales (CIWA scale, AWS scale):
Grading of course of the withdrawal symptoms
- Psychopathology scales
- Craving scale (OCDS-G scale)
- Information about the course of the detoxification
with the patient and spouse
Contraindications: Heavy organic, psychiatric or
neurologic diseases
Therapy:
- RR > $160 / 110$ a./o. Tachycardia: Clonidine $75-\mu g$ capsules: $3 \times 2 /$ day
- Sleep disturbance, anxiety, unrest: Doxepin $25 \mathrm{mg:} 3 \times 2 /$ day
- Seizure prophylaxis: Carbamazepin $600-800 \mathrm{mg} /$ day
- Therapeutic sessions

Fig. 1. Overview: Clinical concep outpatient treatment facility.

Days 1-5 of detoxification
Daily medical examination
- Breathalyzer
- Neurological, psychiatric examination
- Withdrawal scale: Check RR, pulse,
sweat, tremor, breath frequence,
temperature, cerebral and emotional
symptoms
- Craving scale
- Medication (if necessary)
- Motivational interviewing
Last day of detoxification
- Neurological/psychiatric examination
- Withdrawal scale
- Psychopathology scales
- Draving scale

times a week. An extensive internal/neurological examination and a detailed psychodiagnostic examination are performed. The weekly setting during the motivational phase consists of a 'motivationalenhancement group' (cognitive-oriented therapy, including Jacobson progressive muscular relaxation) and a so-called 'support group' (body and emotional-oriented therapy, autogenic training) and four individual psychotherapy/medical sessions.

\section{Rehabilitation Phase}

The therapeutic concept is integrative and eclectic, and includes different psychotherapeutic methods and approaches.

The therapy program comprises 80 to maximum 120 therapy sessions, mostly group therapy but also individual therapy, including behavioral/cognitive, psychodynamic and systemic oriented therapy sessions. Optional elements are self-help groups, but also other elements such as psychodrama or muscular relaxation, among others, are also used.

During the entire treatment abstinence is checked by repeated breathalyzer tests as well as blood laboratory tests. The therapeutic team comprise 2-3 psychiatrists (physicians), 2 full-time psychotherapists, several part-time psychologists, and 1 social worker. As for inpatient treatment clinical coworkers of the outpatient clinic must fulfill qualifications to be acknowledged by pension funds as therapists.

The outcome of the rehabilitation program has been the subject of research before. An earlier retrospective follow-up study had revealed a $46 \%$ abstinence rate 18 months after treatment [Soyka et al., 1997]; a prospective 3-year follow-up study is currently being conducted. The different treatment steps and options of the outpatient clinic are given in figure 1 .

\section{Outpatient Detoxification Model}

The outpatient detoxification program was developed by the principal investigator (first author) and introduced into clinical practice in 1998 [for methods see, Soyka et al., 1999, 2001].
Patients are initially seen in the outpatient clinic. Patients are referred for participation in the two-step rehabilitation program described above. Before that detoxification must have been performed either on an outpatient or inpatient basis. After detoxification patients are supposed to enter the alcohol treatment program. The time schedule of outpatient detoxification is given in figure 1.

A major tool is the assessment of possible risk factors before treatment begin. Patients are carefully screened for major psychiatric (depression, schizophrenia, polytoxicomania, etc.) and somatic/neurologic disorders (seizures, history of alcohol psychoses) using a number of diagnostic instruments (ECG, drug screening, detailed laboratory examination).

For assessment of alcohol withdrawal the CIWA-A scale [Shaw et al., 1981; Sullivan et al., 1989] is used. The validated German version of the CIWA-A scale by Stuppaeck et al. [1994] is a 12-item scale which comprises following items: blood pressure (RR), pulse rate, respiratory rate, body temperature, seizures, nausea/vomiting, tremor, hyperhidrosis, tactile/auditory/visual disturbances, orientation, concentration, nervousness/anxiety and headache. In contrast to the original scale by Sullivan et al. [1989] with grades from 0 to 7 the German CIWA-A-scale uses grades from 1 (non existent) to 6 (maximum), except for seizures. The total minimum score of the scale is 11 (no symptoms).

Additionally the Alcohol Withdrawal Scale (AWS) is used [Wetterling et al., 1995a, b]. This is an 11-item scale with grades from $0=$ none to $3=$ severe.

\section{Procedure}

During detoxification, patients are seen on a daily basis for 5-7 (maximum 10) days. Beside somatic and psychiatric examinations, group therapy and individual motivational-oriented psychotherapy (minimum $3 \mathrm{~h}$ during detoxification) are offered during treatment (fig. 2; see also below). Withdrawal symptoms were measured on a daily basis (CIWA-A scale, AWS scale). Patients have to give written consent before starting treatment. 
In case of severe medical complications patients will be transferred to hospital, preferably the Psychiatric Hospital of the University of Munich.

\section{Medication}

Patients received vitamins (especially $\mathrm{B} 1)$ and minerals $(\mathrm{Na}, \mathrm{K}$, $\mathrm{Mg}$ ) if necessary. Although medication in general was given on an individualized decision basis, the literature [Mayo-Smith, 1997] and our own experience suggest that patients with a CIWA-A score of $>16$ or an AWS score of $>6$ require medication. If the patient experienced withdrawal symptoms as measured by the AWS ( $>6$ mean value for withdrawal symptoms) and the CIWA-A scale ( $>16)$ pharmacotherapy was initiated.

Initially to avoid tranquilizers/hypnotics with abuse potential (benzodiazepines and chlormethiazole) a symptom-triggered pharmacological treatment either with doxepine $(25-50 \mathrm{mg}$, maximum $100 \mathrm{mg}$ ) or clonidine (systolic hypertension, RR > $180 \mathrm{~mm} \mathrm{Hg}$ ) was initiated. In leading German textbooks of clinical psychopharmacology this antidepressant is recommended for treatment of alcohol withdrawal [Benkert and Hippius, 1996]. Although no standard fixed dose regime was used the usual medication scheme in case of hypertension $(>160 / 100 \mathrm{~mm} \mathrm{Hg})$ was $3 \times 2 \times 75 \mu \mathrm{g}$ clonidine on days 1 and 2 and $1-3 \times 75 \mu \mathrm{g}$ on day 3 . Clonidine is a first-line medication for hypertension in alcohol withdrawal [for review see, Soyka et al., 1999]. For sleep disorder $25 \mathrm{mg}$ doxepine was given in the evening; in case of severe agitation, restlessness or other vegetative symptomatology the dose was increased to $3 \times 25 \mathrm{mg}$ doxepine. Later on during the program a combination of carbamazepine and tiapride was used for outpatient detoxification [Soyka et al., 2002].

\section{Motivational Psychotherapy during Detoxification}

Based on the concept of Miller and Rollnick [1991, 1999], the 3-hour motivational oriented psychotherapy during outpatient treatment aimed to motivate patient for further therapy and abstinence. In two individual sessions the patient's alcohol history and its consequences for work, health and family were addressed. The patient was advised to remain abstinent in the future, and arguments for (or against) further abstinence were balanced. In the next step the patient's personal situation and future perspectives were addressed. Possible deficits in various areas were the subject of discussion. The patient was supposed to learn that his psychosocial situation (workplace, family, finance) will benefit from further abstinence. Finally possible psychotherapeutic interventions in the post-detoxification period were outlined and possibly organized. Based on the patient's own alcohol history further alcohol therapy was initiated focusing on outpatient rehabilitation.

The motivational group therapy session had the main aim to reduce the patient's resistance to treatment and was also used as a diagnostic instrument to explore the patient's interaction with others (feedback). In the group therapy the patient could also report his personal experience with alcohol.

\section{Follow-Up Interview}

Patients were personally interviewed and examined after 12 months. Breathalyzer tests and if possible collateral information from the spouse or other family members or GPs were used to verify/ exclude abstinence. Biological parameters like $\gamma$-glutamyltransferase and carbohydrate-deficient transferrin were measured if the patient's self-report seemed to be inconsistent with the clinical findings.

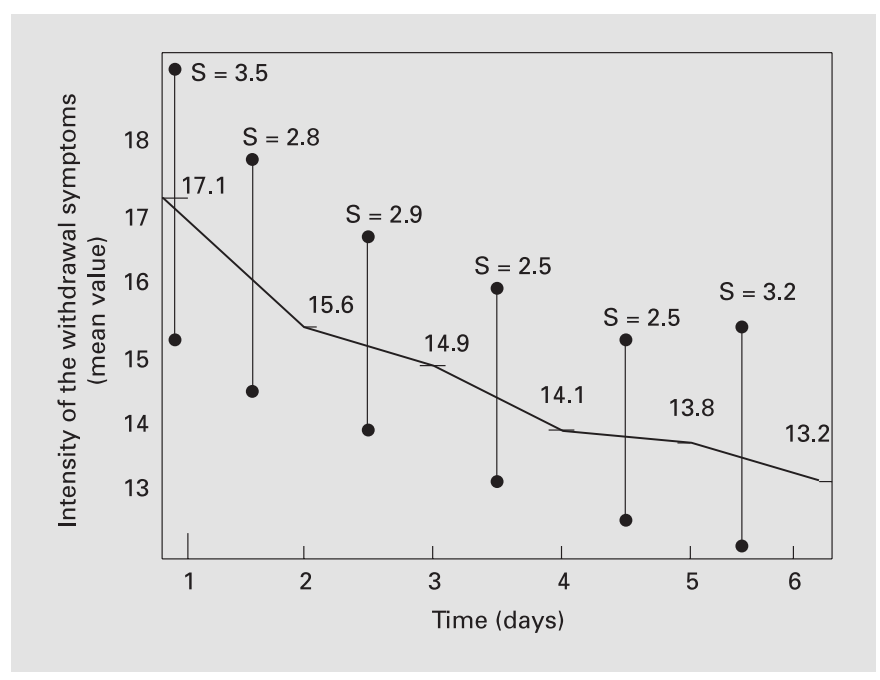

Fig. 2. Withdrawal symptoms over 6 days as measured by the CIWA-A scale (mean values). $\mathrm{S}=$ Standard deviation.

Table 1. Baseline sociodemographic characteristics of patients

\begin{tabular}{lrr}
\hline & $\mathrm{n}$ & $\%$ \\
\hline Total & 331 & 100 \\
Male & 222 & 67 \\
Female & 109 & 33 \\
Working/housewife & 247 & 75 \\
Unemployed & 84 & 25 \\
Living in partnership & 232 & 70 \\
Divorced & 95 & 28 \\
Single at present & 99 & 30 \\
Children & 158 & 48 \\
No children & 173 & 52 \\
Previous alcohol treatment & & \\
$\quad$ (rehabilitation, psychotherapy) & 106 & 32 \\
Previous alcohol detoxification & 149 & 45 \\
\end{tabular}

\section{Results}

Of 557 patients screened between July 1998 and June 2003, $331(59 \%)$ entered the program. For medical reasons 223 patients had to be transferred to a hospital. Three patients decided to be detoxified by their general practitioner. Patient characteristics are given in table 1. Of the 331 patients 222 (67\%) were male and 109 (33\%) female. Mean age was 44.3 (24-72, SD 8.5) years, mean duration of alcohol dependence 9.8 (SD 9.0) years. The 


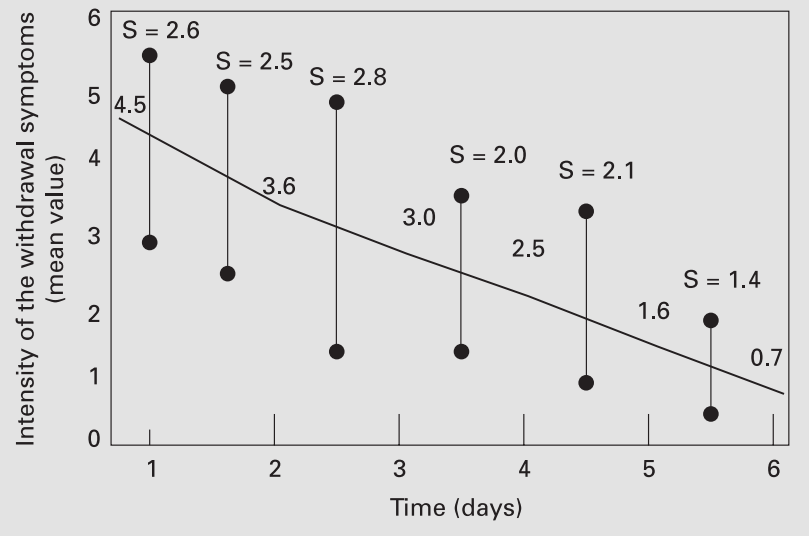

Fig. 3. Withdrawal symptoms over 6 days as measured by the AWS scale (mean values). $\mathrm{S}=$ Standard deviation.

mean $\gamma$-glutamyltransferase value was 99 (SD 11.0) U/1 at baseline. Mean alcohol consumption in the month prior to baseline was reported to be 156 (SD 72) g/day.

106 of 331 patients (32\%) had been previously treated for alcohol dependence in a rehabilitation program. 149 of $331(45 \%)$ had been treated as inpatients for alcohol detoxification.

Although patients were asked to reduce alcohol consumption before treatment, breathalyzer tests showed that 99 of $331(30 \%)$ patients were still intoxicated at the begin of withdrawal (blood alcohol concentration 0.1 and 2.7).

195 (58.9\%) patients received medication. Withdrawal symptoms were measured on a daily basis (13-item CIWA-A scale, AWS scale). There were no serious medical complications, especially no seizures, alcohol withdrawal delirium or other neurological disorders.

58 of 195 (30\%) patients received doxepine, 68 of 195 (35\%) clonidine, 29 of $195(15 \%)$ in combination, 39 of $195(20 \%)$ patients other medications ( $\beta$-blocker, carbamazepine/tiapride, other antidepressants).

The mean CIWA-A score on day 1 was 18.1 (13-27) which gradually declined over the treatment period (fig. 2, 3). The same was true for the AWS score.

\section{Outcome}

An overview of treatment outcome in patients admitted for alcohol detoxification is given in figures 4 and 5 .

Of the 331 patients enrolled, $312(94 \%)$ successfully terminated treatment. $19(6 \%)$ patients dropped out of treatment. Reasons for dropping out were: alcohol relapse $(\mathrm{n}=10)$; lack of motivation; noncompliance, or problems at work or with health insurance $(n=9)$.

Of the 312 patients who successfully ended outpatient detoxification, 301 (96\%) entered the first motivationaloriented treatment phase at the outpatient clinic. $11(4 \%)$ opted for psychotherapy in another facility.

\section{2-Month Outcome}

Patients were examined 12 months after outpatient detoxification by personal interview. Data of the 12month follow-up evaluation indicate the following results. $114(38 \%)$ patients dropped out of treatment during the first 3-month motivational treatment phase primarily because of relapse to alcohol. $48(16 \%)$ dropped out of treatment during the consecutive 6- to 8-month rehabilitation phase, while 97 (32\%) of the 301 patients completed the rehabilitation phase without any relapse.

\section{Discussion}

While in Scandinavia, Great Britain and the US a number of treatment models for outpatient alcohol detoxification have been proposed and evaluated [Alsen, 1975; Alterman et al., 1998; Bjorkquist et al., 1976, O’Connor et al., 1991; Webb and Unwin, 1988], mostly in specialized outpatient clinics but partially also at home [Stockwell et al., 1986], to date in Germany outpatient detoxification is hardly practiced, at least on a structured basis. The literature on this subject is still surprisingly limited. In 1998 Wiseman et al. reported a completion rate of $85 \%$, a figure similar to those found in other studies [Collins et al., 1990; Alterman et al., 1998; O'Connor et al., 1991; Webb and Unwin, 1998; Stockwell et al., 1986; Hayashida et al., 1989; Stinnet, 1982; Feldman et al., 1975]. Still, little is known about the mid- and long-term efficacy of outpatient detoxification concerning abstinence and motivation of patients for further treatment.

We report results on the efficacy of an outpatient alcohol detoxification program which was launched after intensive negotiations with major health care insurances in the outer Munich area in 1998. The study was performed in an outpatient alcohol clinic which already offered a comprehensive outpatient rehabilitation program [Soyka et al., 1997] and had expressed its interest in a collaboration in this area. The results of this treatment program with a $94 \%$ completion rate of outpatient detoxification support the positive results reported by Wiseman et al. [1997, 1998] and others [Collins et al., 1990; Alterman et al., 1998; Bjorkquist et al., 1976; Hayashida 


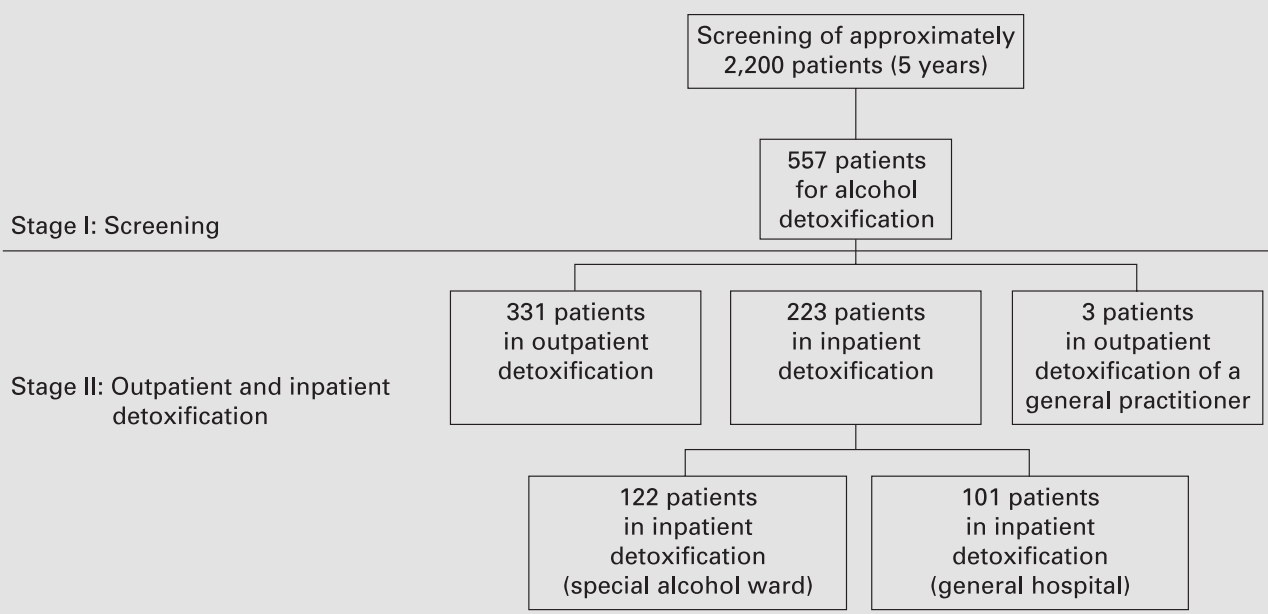

Fig. 4. Overview of alcohol inpatient and outpatient detoxification.

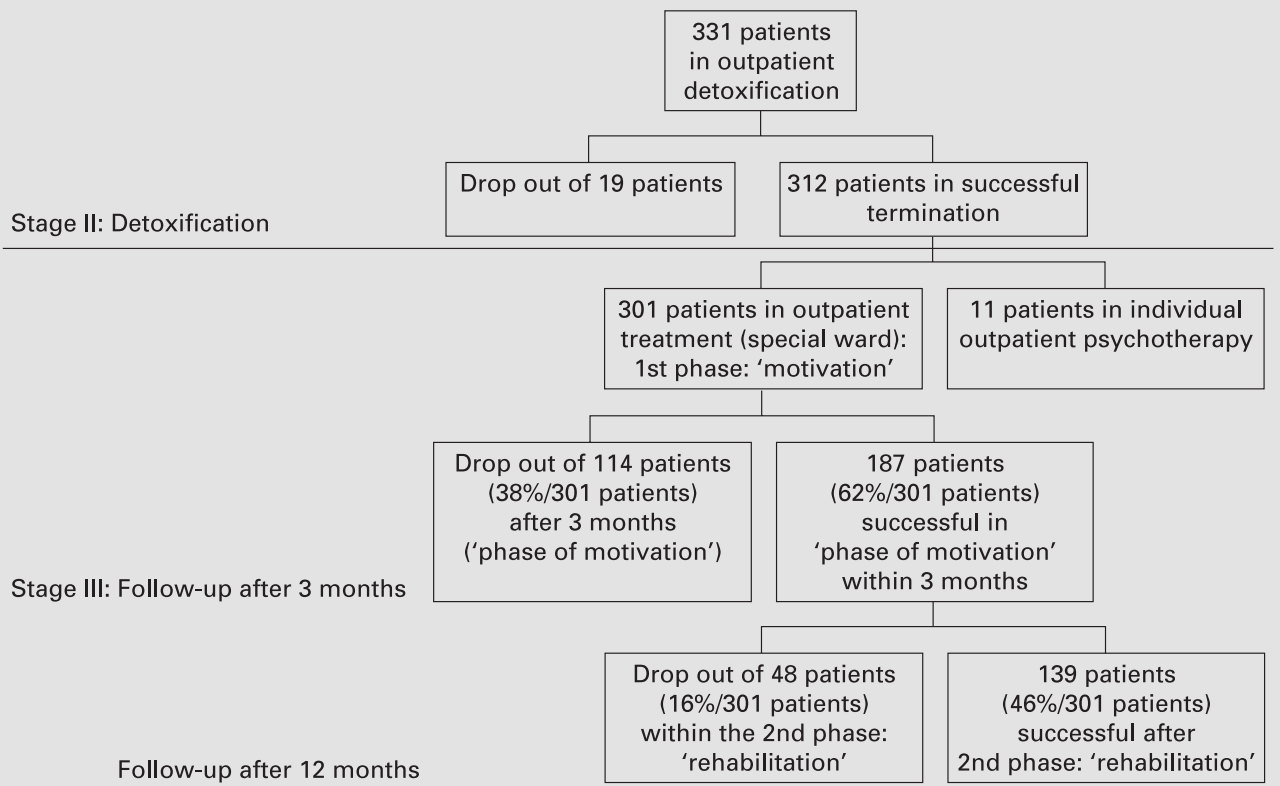

Fig. 5. Clinical outcome after outpatient treatment. 
et al., 1989] and suggest that outpatient alcohol detoxification can be considered a safe and effective treatment option for a subgroup of alcoholic patients.

There are several limitations to our study. First no control group could be studied to compare effects of outpatient vs. inpatient or the efficacy of the psychotherapeutic interventions compared to a basically somatic detoxification.

While this study was primarily designed to study the feasibility and safety of the outpatient treatment model, future research will address the mid- and long-term outcome of outpatient detoxification compared to inpatient treatment.

Second, both for inpatient and outpatient treatment of alcoholics, setting effects have to be considered [Finney et al., 1996]. Although the patients included in our sample had a long-term alcohol history, the level of psychiatric comorbidity was probably lower compared to patients seen in other detoxification wards. In other studies patients with high psychiatric severity and/or poor social support were found to benefit more from inpatient compared to outpatient treatment [Pettinati et al., 1993].

From a methodological point of view it seems noteworthy that the treatment program evaluated in our study had been conducted in a highly structured outpatient clinic offering an intensive post-detoxification outpatient treatment rehabilitation program. Studies in less intensive outpatient settings may reveal less favorable results. The clinical management of withdrawal symptoms on an outpatient basis, including adequate dosages of appropriate medications and treatment of comorbid psychiatric or medical disorders, deserves future attention. In most of the studies quoted about hypnotics, benzodiazepines were predominantly used for treatment of withdrawal symptoms either in a fixed dosage regime [Collins et al., 1990] or on an individualized, symptom-oriented basis [Wiseman et al., 1998]. Other authors favor the use of anticon- vulsants [Longo et al., 2002], especially carbamazepine [Malcolm et al., 2002]. Although the effectiveness of benzodiazepines in the treatment of alcohol withdrawal symptoms has clearly been demonstrated, its use in outpatient withdrawal may be discussed and considered with caution. At least in Germany the prescription of benzodiazepines and other hypnotics such as chlormethiazole to alcoholics on an outpatient basis is controversial predominantly because of the risk of over-sedation/intoxication and the apparent abuse potential. In the program reported, doxepine and/or clonidine respectively carbamazepine/tiapride were given if necessary and the clinical impression and treatment results concerning medical complications and feasibility of treatment were quite favorable. Since this study was not primarily designed to evaluate different pharmacological regimes in outpatient detoxification, these results may be considered to be preliminary in some respects but future studies and a more detailed analysis of this continuing program may address this question in more detail.

In conclusion, the clinical results of the outpatient detoxification program presented suggest that this therapeutic approach is safe and practical. Future studies should focus on different treatment settings (outpatient clinic vs. home detoxification), individual variables predicting outcome, evaluation of different pharmacological regimes for outpatient treatment including antidepressants and carbamazepine [Bjorkquist et al., 1976] that might minimize the risk for secondary drug dependence and socioeconomic factors (cost-benefit ratio), among others.

\section{Acknowledgement}

This study was supported as a model project by public health insurers.

\section{References}

Alsen M: Outpatient treatment of acute withdrawal states. Br J Addict Alcohol Other Drugs 1975; 70(suppl 1):53-63.

Alterman AI, Hayashida M, O'Brien CP: Treatment response and safety of ambulatory medical detoxification. J Stud Alcohol 1998;49 160-166.

American Psychiatric Association: Diagnostic and Statistic Manual of Mental Disorders, ed 4 (DSM-IV). Washington, American Psychiatric Press, 1994
Benkert O, Hippius H: Psychiatrische Pharmakotherapie, ed 6. Berlin, Springer, 1996.

Bjorkquist SE, Isohanni M, Makela R, et al: Ambulant treatment of alcohol withdrawal symptoms with carbamazepine: A formal multicentre double-blind comparison with placebo. Acta Psychiatr Scand 1976;53:333-342.

Collins MN, Burns T, Van den Berk PAH, Tubman GF: A structured programme for out-patient alcohol detoxification. Br J Psychiatry 1990; 56:871-874.
Cornwall A, Blood L: Inpatients versus day treatment for substance abusing adolescents. J Nerv Ment Dis 1998;186:580-582.

Dilling H, Mombour W, Schmidt MH, SchulteWarkwort E (eds): WHO: Internationale Klassifikation psychischer Störungen ICD-10 Kapitel V (F) Forschungskriterien. Bern, Huber, 1994. 
Ehrenreich H, Krampe H, Wagner T, Jahn H, Jacobs S, Maul O, Sieg S, Driessen M, Schneider U, Kunze H, Rusteberg W, HavemannReinecke U, Rüther E, Poser W: Outpatient long-term intensive therapy for alcoholics, 'OLITA': Re-considering severe alcoholism, disease and treatment. Suchtmed 2000;2:221222.

Feldman DJ, Pattison EM, Sobell LC, et al: Outpatient alcohol detoxification: Initial findings on 564 patients. Am J Psychiatry 1975;132: 407-412.

Feuerlein W, Küfner H, Soyka M: Alkoholismus Missbrauch und Abhängigkeit, 5. Aufl. Stuttgart, Thieme, 1998.

Fiellin DA, Reid MC, O'Connor PG: Outpatient management of patients with alcohol problems. Ann Intern Med 2000;133:815-827.

Finney JW, Hahn AC, Moos RH: The effectiveness of inpatient treatment and outpatient treatment for alcohol abuse: The need to focus on mediators and moderators of setting effects. Addiction 1996;91:1773-1796.

Hayashida M, Alterman AI, McLellan AT, et al: Comparative effectiveness and costs of inpatient and outpatient detoxification of patients with mild-to-moderate alcohol withdrawal syndrome. N Engl J Med 1989;320:358-365.

John U: A motivational approach to the treatment of alcoholism in the Federal Republic of Germany. Alcohol Treat Q 1991;8:83-92.

John U, Veltrup C, Driessen M, Wetterling T, Dilling H: Motivationsarbeit mit Alkoholabhängigen. Freiburg, Lambertus, 2000.

Longo LP, Campbell T, Hubatch S: Divalproex sodium (Depakote) for alcohol withdrawal and relapse prevention. J Addict Dis 2002;21:5564.

Malcolm R, Myrick H, Roberst J, Wang W, Anton RF: The differential effects of medication on mood, sleep disturbance, and work ability in outpatient alcohol detoxification. Am J Addict 2002;11:141-150.

Mann KF: Neue ärztliche Aufgaben bei Alkoholproblemen. Von der Behandlungskette zum Behandlungsnetz. Dt Ärzteblatt 2002;99: B515-B521.

Mayo-Smith MF: Pharmacological management of alcohol withdrawal. A meta-analysis and evidence-based practice guideline. American Society of Addiction Medicine, Working Group on Pharmacological Management of Alcohol Withdrawal. JAMA 1997;278:144-151.
McCrady BS, Langenbucher JW: Alcohol treatment and health care system reform. Arch Gen Psychiatry 1996;53:737-746.

McKay JR, Alterman AI, McLellan T, Snider EC, O'Brien CP: Effect of random versus nonrandom assignment in a comparison of inpatient and day hospital rehabilitation for male alcoholics. J Consult Clin Psychol 1995;63:70-78.

McKay JR, McLellan AT, Alterman AI, Cacciola JS, Rutherford MJ, O'Brien CP: Predictors of participation in aftercare sessions and self-help groups following completion of intensive outpatient treatment for substance abuse. J Stud Alcohol 1998;59:152-162.

Miller WR, Rollnick S: Motivational Interviewing. New York, Guilford, 1991.

Miller WR, Rollnick S: Motivierende Gesprächsführung. Freiburg, Lambertus, 1999.

O'Connor PG, Gottlieb LD, Kraus ML, Segal SR, Horwitz RI: Social and clinical features as predictors of outcome in outpatient alcohol withdrawal. J Gen Intern Med 1991;6:312-316.

Pettinati HM, Meyers K, Jensen JM, Kaplan F, Evans BD: Inpatient vs outpatient treatment for substance dependence revisited. Psychiatr Q 1993;64:173-182.

Prater CD, Miller KE, Zylstra RG: Outpatient detoxification of the addicted or alcoholic patient. Am Fam Physician 1999;60:1175-1183.

Schwoon DR: Motivationsbehandlung bei Alkoholkranken; in Schwoon DR, Krausz M (eds): Suchtkranke: Die ungeliebten Kinder der Psychiatrie. Stuttgart, Enke, 1990, pp 166-181.

Sellers EM, Naranjo CA, Harrison M, Devenyi P, Roach C, Sykora K: Diazepam loading: Simplified treatment of alcohol withdrawal. Clin Pharmacol Ther 1983;34:822-826.

Shaw JM, Kolesar GS, Sellers EM, Kaplan HL, Sandor P: Development of optimal treatment tactics for alcohol withdrawal. I. Assessment and effectiveness of supportive care. J Clin Psychopharmacol 1981;1:382-389.

Soyka M, Hasemann S, Scharfenberg CD, Löhnert B, Bottlender M: Prospektive Untersuchung zur Effizienz der ambulanten Entwöhnungstherapie bei Alkoholabhängigen: Ergebnisse zur Haltequote und Katamnese. Nervenarzt 2003;74:226-234.

Soyka M, Horak M, Löhnert B, Löhnert E, Rüster P, Möller HJ: Ambulante Entgiftung Alkoholabhängiger - Ein Modellversuch. Nervenheilkunde 1999;8:147-152.
Soyka M, Horak M, Morhart V, Möller HJ: Modellprojekt 'qualifizierte ambulante Entgiftung' Nervenarzt 2001;72:565-569.

Soyka M, Kirchmayer C, Kotter G, John C, Löhnert E, Möller HJ: Neue Möglichkeiten der Therapie und Rehabilitation alkoholabhängiger Patienten - Katamnestische Untersuchung zur Effizienz ambulanter Entwöhnungstherapien am Beispiel einer Modelleinrichtung. Fortschr Neurol Psychiatr 1997;65:407-412.

Soyka M, Morhart-Klute V, Horak M: A combination of carbamazepine/tiapride in outpatient alcohol detoxification - Results from an open clinical study. Eur Arch Psychiatry Clin Neurosci 2002;252:197-200

Stinnett JL: Outpatient detoxification of the alcoholic. Int J Addict 1982;17:1031-1046.

Stockwell T, Bolt E, Hooper J: Detoxification from alcohol at home managed by general practitioners. Br Med J 1986;292:733-735.

Stuppaeck CH, Barnas C, Falk M, Guenther V, Hummer M, Oberbauer H, Pycha R, Whitworth B, Fleischhacker WW: Assessment of the alcohol withdrawal syndrome - Validity and reliability of the translated and modified Clinical Institute Withdrawal Assessment for Alcohol scale (CIWA-A). Addiction 1994;89:12871292.

Sullivan JT, Sykora K, Schneiderman J, Neranjo CA, Sellers EM: Assessment of alcohol withdrawal: The revised clinical institute withdrawal scale (CIWA-Ar). Br J Addict 1989;84:13531357 .

Webb M, Unwin A: The outcome of outpatient withdrawal from alcohol. Br J Addict 1988;83: 929-934.

Wetterling T: Lübecker Alkoholentzugs-RisikoSkala (LARS); Med Thesis, Lübeck, 1995a.

Wetterling T: Skala zur Erfassung des Schweregrads eines Alkoholentzugssyndroms (AESScale) - Erste klinische Erfahrungen. Sucht 1995a(suppl 1):41-43.

Willenbring ML, Olson DH, Bielinski J: Integrated outpatients treatment for medically ill alcoholic men: Results from a quasi-experimental study. J Stud Alcohol 1995;56:337-343.

Wiseman EJ, Henderson KL, Briggs MJ: Individualized treatment for outpatients withdrawing from alcohol. J Clin Psychiatry 1998;59:289_ 293.

Wiseman EJ, Henderson KL, Briggs MJ: Outcomes of patients in a VA ambulatory detoxification program. Psychiatry Serv 1997;48:200-203. 